\title{
Survey on the nucleate pool boiling of hydrogen and its limits
}

Touhami BAKI

DOI: 10.30464/jmee.2020.4.2.157

Cite this article as:

Baki T. Survey on the nucleate pool boiling of hydrogen and its limits. Journal of Mechanical and Energy Engineering, Vol. 4(44), No. 2, 2020, pp. 157-166.

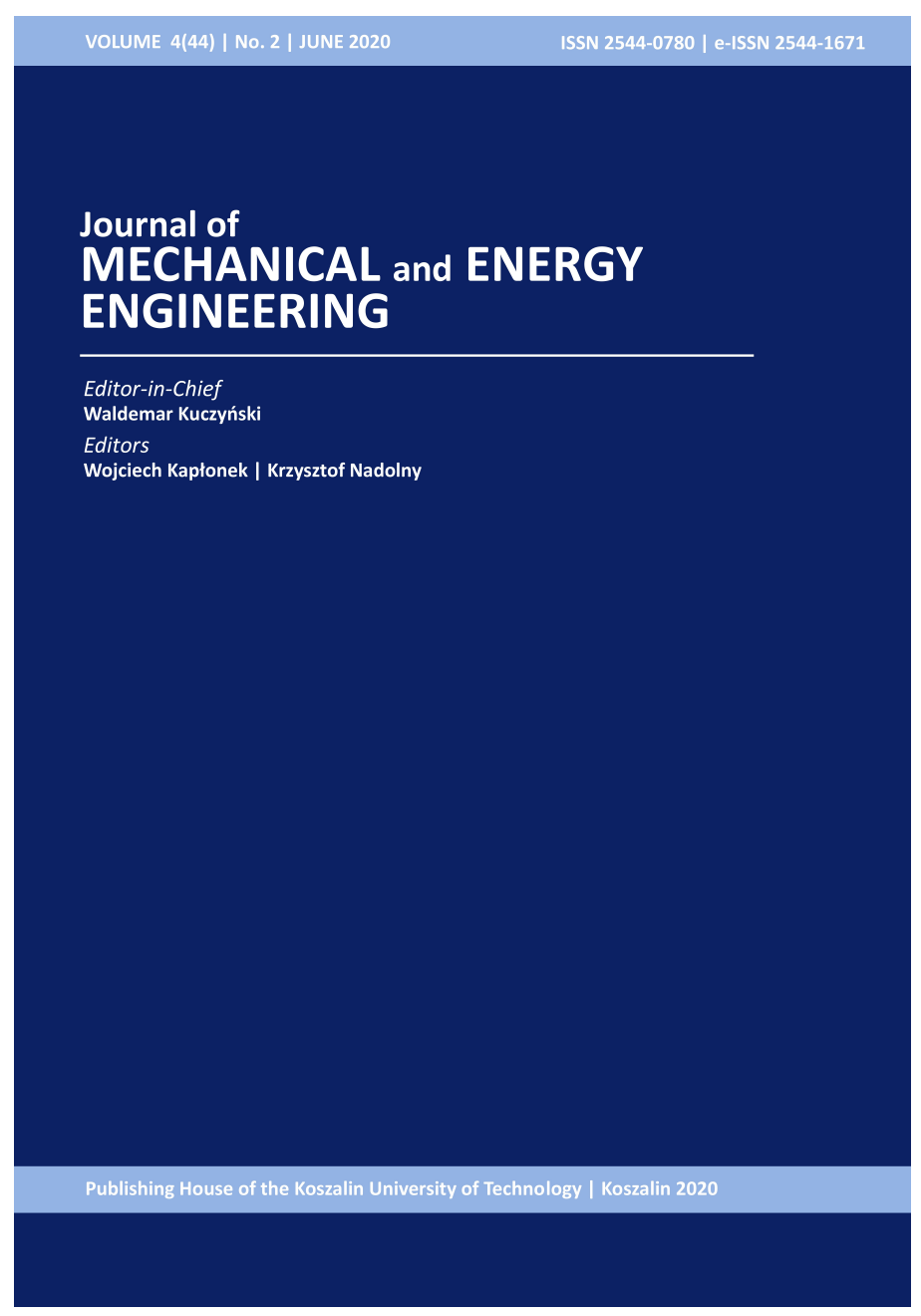

Journal of Mechanical and Energy Engineering

Website: jmee.tu.koszalin.pl

ISSN (Print): 2544-0780

ISSN (Online): 2544-1671

Volume: 4(44)

Number: 2

Year: 2020

Pages: 157-166

Article Info:

Received 14 April 2020

Accepted 25 May 2020

\section{Open Access}

This article is distributed under the terms of the Creative Commons Attribution 4.0 (CC BY 4.0) International License (http://creativecommons.org/licenses/by/4.0/), which permits unrestricted use, distribution, and reproduction in any medium, provided you give appropriate credit to the original author(s) and the source, provide a link to the Creative Commons license, and indicate if changes were made. 


\title{
SURVEY ON THE NUCLEATE POOL BOILING OF HYDROGEN AND ITS LIMITS
}

\author{
Touhami BAKI ${ }^{*}$ \\ ${ }^{1 *}$ Faculty of Mechanics, Gaseous Fuels and Environment Laboratory, \\ University of Sciences and Technology of Oran Mohamed Boudiaf (USTO-MB), \\ El Mnaouer, BP1505, Bir El Djir 31000, Oran, Algeria, \\ e-mail : touhami.baki@univ-usto.dz
}

(Received 14 April 2020, Accepted 25 May 2020)

\begin{abstract}
Nucleate pool boiling is a very efficient transfer regime with low temperature gradients, bounded between two heat flux values and which border transitions to other regimes, this phenomenon is well framed with correlations. Our study aims to clarify the applicability of this regime to liquid hydrogen and to develop reliable correlations for a useful and qualitative agreement. An exhaustive review on the nucleate pool boiling of hydrogen and the limits of this regime, whether are the onset nucleate boiling (ONB) and the critical heat flux (CHF) was made, allowing the collection of more than 1400 points from experimental setups, highlighting a variety of parameters. Five predictive correlations were drawn from the literature, graphical and statistical comparisons were made, two in five reveal acceptable results. After analysis of the experimental data, new correlations were developed and compared with the data collected, convincing results were obtained and discussed. A simple form was expressed for the heat flux $q_{O N B}=550 \Delta T^{1.32}$, shows better predicted values; convincing results of the (CHF) have been found on modified correlation, and the CHF value reaches a maximum of $148 \times 10^{3} \mathrm{~W} / \mathrm{m}^{2}$ for a reduced pressure at 0.35 . A nucleate boiling correlation suitable for hydrogen has been developed.
\end{abstract}

Keywords: hydrogen; boiling; onset nucleate boiling; critical heat flux; correlation.

\section{INTRODUCTION}

$H$, is the chemical symbol of hydrogen, composed of a proton and an electron which makes it the simplest and lightest element [1], at room temperature hydrogen is colorless, odorless and flammable, two atoms forms the gas $H_{2}$ [2]. It is the most abundant element in the universe, on earth it mainly occurs in a combined form like water, organic compounds and hydrocarbons, only a few traces of hydrogen are present in the atmosphere [3].

A fair amount of research is underway for the development of hydrogen generation systems, the most suitable and most used technology is the reforming of hydrocarbons. Alternative processes based on renewable resources such as biomass and water are developed, in order to reduce the impact of fossil materials [4]. Other technologies exist, such as direct thermal decomposition, thermolysis, photolysis and thermochemical transformations where hydrogen is produced from water, these pathways are under development and have a low efficiency rate [5].

Hydrogen storage is organized into three categories, the first is physical storage where pure hydrogen can be in the form of gas or liquid, the second is the storage of molecules by adsorption on or in a metal, the third is a chemical process where hydrogen molecules are absorbed by metallic or chemical hydrides. The methods most commonly used are the storage of hydrogen in gaseous form in bottles at a pressure of 200 bar and at room temperature, and the storage of liquid hydrogen in cryogenic tanks at the temperature of $(21.2 \mathrm{~K})$ and at atmospheric pressure [6, 7].

A distinction was made according to the use of hydrogen between captive hydrogen for the process system as fertilizers production, in refineries, hydrogen fuel for cars, aircraft, rockets, power generation and heating, and hydrogen merchant for a multitude of ending uses produced in one lieu and transported to another. The difference in consumption requires different production, appropriate storage 
systems, transport determined by the location of the production site, the location of customers and their predictable demand [8]. For its excellent characteristics, liquid hydrogen is used as propellant, fuel and cooler in various installations. During the operating processes the liquid will change phase to become vapor, in fact the phenomenon of heat transfer by boiling of hydrogen requires an understanding and mastery in order to optimize the sizing of the equipments.

Richards et al. [9] studied tens of experimental data references relating to the boiling of hydrogen and other cryogenic liquids, and compared them graphically with empirical formulations. Seadres et al. [10] carried out an in-depth study on boiling cryogenic liquids; Some information on experimental heat transfer data for boiling hydrogen and other cryogenic liquids has been extracted from the literature and compared to the theory of boiling. Brantrari et al. [11] conducted a review of the experimental data on the boiling of hydrogen and three other cryogenic liquids and compared them graphically and statistically with predictive correlations, the authors indicated the limit of correlations which do not take into account certain effects of variables not included in the correlations. Drayer [12] compared the heat flux predicted by eleven correlations with the experimental data for nucleate boiling of liquid hydrogen, only three correlations were in good agreement with the experimental data. Dougall [13] has researched cryogenic fluids among them hydrogen and other fluids as well as the correlations applicable for nucleate pool boiling, and other boiling regimes. Wang et al. [14] studied the boiling of hydrogen and analyzed experimental data from the literature; correlations giving the heat flux of nucleate and film boiling were compared with the experimental data then improved, as well as the minimum and maximum critical heat flux.

The present work consists of experiments review of nucleate pool boiling and its limits of onset and critical heat flux, experimental data were then recovered and compared to the know correlations. New correlations were made to improve the predicted results.

\section{BOILING CURVE}

Boiling is a phase change phenomenon where bubbles forms on the hot surface in contact with a fluid; nucleate boiling is a very efficient mode of heat transfer. Pool boiling takes place when the liquid at saturation temperature is at rest in contact with a hot wall and turns into vapor. Figure 1 shows us a qualitative approach to the relationship between the heat flux q passing through a wall and the overheating; $\Delta T$ the superheat is the difference in temperature of the wall and the saturation temperature of the fluid for a given pressure. At the start, the heat flux passing through the wall will correspond to a temperature difference at point $\mathrm{A}$, by increasing the heat flux $\mathrm{q}$ by getting closer to point $\mathrm{B}$, on the section $\mathrm{AB}$ the heat transfer mode is natural convection. In increasing the heat flux more, we take off from point $B$ then passes to point $\mathrm{C}$, where there appear the first bubbles, we change the heat transfer mode, it is the beginning of boiling. The point $\mathrm{C}$ called Onset Nucleate Boiling (ONB), marks the beginning of the nucleate boiling, when the heat flux increases there appears a large number of nucleation sites, the boiling becomes very intense and the hot wall will be covered with bubbles over the surface. The point $\mathrm{D}$ which marks the limit of the Critical Heat Flux (CHF), the temperature of the wall increases rapidly until the intersection with the curve EF; in this section, the film's boiling regime supervene. Likewise, for a decreasing heat flux, one passes from point $\mathrm{F}$ to point $\mathrm{E}$, at this point the temperature rapidly decreases up to the intersection with the section of the curve CD.

In our study one interests in the section of curve $\mathrm{CD}$, located between two transitions of heat transfer modes on one side natural convection and film boiling on the other.

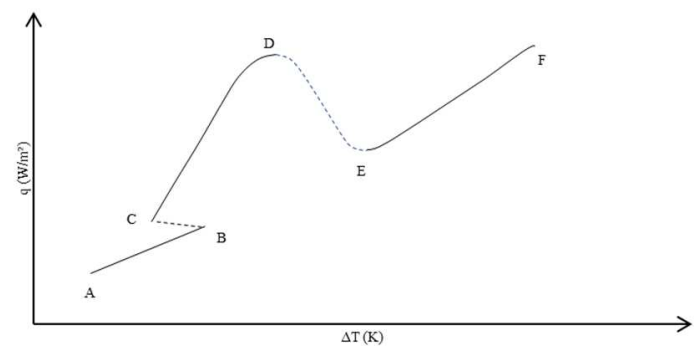

Fig. 1. Boiling curve

\section{REVIEW OF EXPERIMENTAL DATA AND CORRELATIONS}

Knowledge of the parameters which influence boiling in order to limit the formation of bubbles, or to produce steam without reaching the critical limit remains essential. Sets of experimental assemblies have been developed to study nucleate boiling, to identify the beginning of boiling and the limit of critical flux. An overall review and collection of experimental data relating to nucleate boiling [15-31], ONB [21, 26, 28, 30], and CHF [20, 24, 26, 28-33], was made for the pool boiling of hydrogen under saturation conditions.

\subsection{The ONB review}

Figures Nucleation means the appearance of the first bubbles and the transition from heat transfer mode by natural convection to that of heat transfer in nucleate boiling mode, conditioned by an overheating of the wall and whose heat flux can be determined by the relation of Hsu [34]: 


$$
q_{O N B}=\frac{\lambda L \rho_{v} \Delta T^{2}}{12.8 \sigma T_{\text {sat }}} .
$$

Coeling and Merte [21] studied experimentally the influence of the material, roughness and the orientation of the heating surface, they concluded that the appearance of the first bubbles is directly linked to overheating $\Delta T$ and that the other variables have a weak influence. Kozlov and Nozdrin [26] carried out the experimental study on the nucleation of hydrogen by varying two parameters, namely the pressure and the material of the heating surface. Ohira [28] observed the appearance of the first hydrogen bubble at the Normal Boiling and the Triple points, by modifying the orientation of the hot plate. Shiotsu et al. [30] investigated the nucleation for different pressures by changing the exponential period of a transient regime, they concluded that nucleation was due to a heterogeneous spontaneous appearance.

Figure 2 shows the 66 points grouped from the experiments $[21,26,28,30]$ and indicates a significant dispersion of these points, these latter do not respond to any trend curve which can relate the temperature difference to the heat flux, it can be due to the variety of experimental conditions and uncommon variables treated by each of the experiments.

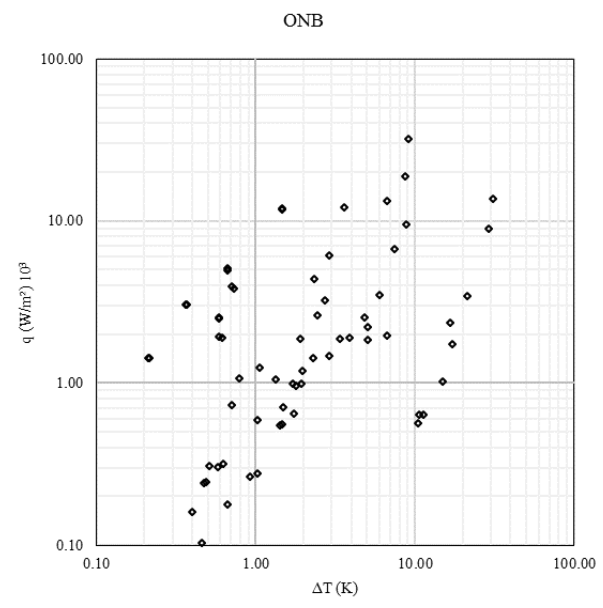

Fig. 2. ONB experiments $[21,26,28,30]$

\subsection{The CHF review}

The CHF is considered as the limit of the heat flux of the nucleate boiling, from this point the temperature increases rapidly to reach very important values, in industry this passage is undesirable since it deteriorates the heating wall. The operating regime of two-phase equipment is always below this critical flux, it can be determined by the following relation of Kutateladze [35]:

$$
q_{c}=C L \rho_{v}\left[\frac{g \sigma\left(\rho_{l}-\rho_{v}\right)}{\rho_{v}^{2}}\right]^{1 / 4}
$$

Significant works has been performed to understand the $\mathrm{CHF}$ behavior and the variables that affect the results. Astruc [20] was able to determine the CHF value experimentally for boiling hydrogen under operating conditions at atmospheric pressure. Bewilogua et al. [24] have experimentally studied the CHF by tuning the ratio of the operating pressure reported to the critical pressure. Kozlov and Nozdrin [26] varied two parameters, the pressure and the nature of the material, to see their influence on the CHF, they concluded that the nature of the material influences weakly, on the other hand the CHF depends on the pressure. Ohira [28] presented the experiments at the Normal Boiling and Triple points, by varying the orientation of the heating surface, he concluded that the CHF is swayed by the heater orientation. Shirai et al. [29] studied the clout of pressure, they found experimentally that the value of CHF increases, reaches a peak and then decreases. Shiotsu et al. [30] have experimentally revealed the impact of the exponential period on the CHF by modifying the pressure. Tatsumoto et al. [31] found the experimental results of the action of pressure on $\mathrm{CHF}$, the latter increases, reaches a peak then decreases. Ohk and Chung [32] visualized experimentally the inclination effect of the wall on the CHF by a non-heating method, and compared the results with existing correlations. Roubeau [33] studied the behavior of the fluid temperature, he noticed that when the temperature increases the CHF increases then it decreases, by passing through a maximum value.

Figure 3 shows the evolution of the $\mathrm{CHF}$ as a function of the ratio of the operating pressure compared to the critical pressure. The curve starts from a low value increases passing through an extremum then tends towards zero at the approach of the pressure critical. Some points are scattered and do not follow the shape of the curve, other points indicate several values of CHF for the same value of the ratio, the peak is reached for a reduced pressure lying between 0.3 and 0,$4 ; 130$ points were collected from experiences [20, 24, 26, 28-33].

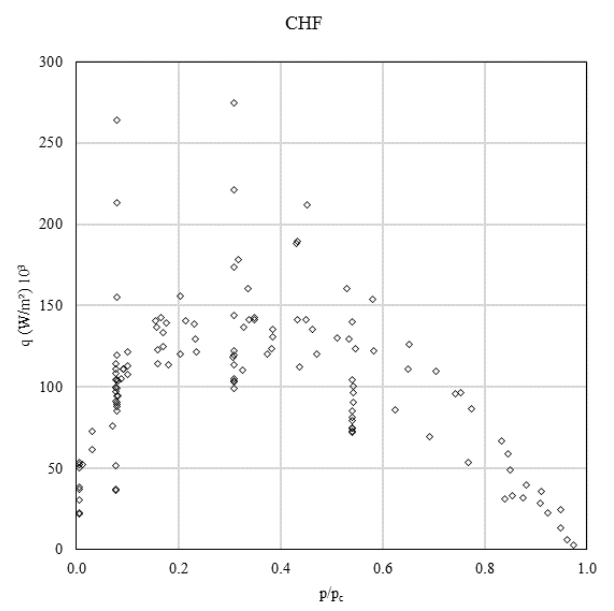

Fig. 3. CHF experiments [20, 24, 26, 28-33] 


\subsection{The nucleate boiling review}

The nucleate boiling is the part located between the two limits ONB and CHF, it is the desired zone of vapor production, where the wall temperature remains relatively higher than a few degrees compared to the saturation temperature.

An exhaustive review of the experimental data was made, presented in table 1 , totaling 1200 points and concerning the nucleate pool boiling of hydrogen under saturation conditions. In this study, the pressure varies from $6.9 \times 10^{3}$ to $11 \times 10^{5} \mathrm{~Pa}$, the heat flux extends over a range of 70 to $220 \times 10^{3} \mathrm{~W} / \mathrm{m}^{2}$, the temperature difference $\Delta T$ is limited between 0.03 and $27.93 \mathrm{~K}$. The analysis of the experiments showed that different geometries were chosen for the body of the heating element, we note a tube [17], a ribbon [19], a cylinder [25], a sphere [22], wires [15, 20, 22], plates $[16,18,29-31]$ and the most used are disks $[21-24$, 26-28]. These heating elements were made of various materials such as Lead, Platinum, Aluminum alloy, Chromel A, Teflon, Glass, Bronze, Steel, Stainless Steel, Manganin and the one that comes back the most is Copper. The state of the hot surface has not been defined for some, qualified as smooth for [16, 23], and defined with a roughness value for $[17,21,25,28]$. The dimensions of the heating elements vary from 0.1 $\mathrm{mm}$ for the diameter of a wire to $560 \mathrm{~mm}$ for the length of a plate. In the analyzed experiments, several variables were treated to determine their effects on the nucleate boiling, one distinguishes the material of the heater $[21,22,26]$, its geometry $[22,26]$, its state of surface [ 21], and its orientation [16,21,27,28]. The effect of pressure has also studied extensively $[16,19$, $24,25,26,28,29,31]$, as well as the direction of the heat flux, ascendant or descendant $[21,22,26-28,30]$, fast or slow [30].

Figure 4 exhibit us the heat flux as a function of the temperature difference for all the experimental data that has been collected, a dispersion of the points over a wide band is noted with homogeneous concentrations, and particularly important in the middle. The dispersion is due to the great variety of experiments realized and the different variables studied; another observation is that all the data symbolized by points on the graph follow a privileged direction.

Many correlations have been developed to determine the HTC (Heat Transfer Coefficient), the very first was the work of Kruzhlin [36], since several other correlations have been developed, our choice fell on five correlations [36-40]. All the correlations allow the HTC to be calculated directly, or indirectly through the heat flux or the Nusselt number. The predicted values are determined as a function of the heat flux, the thermo-physical characteristics of the fluid and the pressure.
The correlation (3) of Kruzhlin [36] makes it possible to calculate the HTC according to the heat flux, thermo-physical parameters, the capillary length, the saturation temperature and the density ratio, it is written in the next form:

$$
\frac{h l_{c}}{\lambda}=0.082\left(\frac{L q}{g T_{\text {Sat }} \lambda} \frac{\rho_{v}}{\rho_{l}-\rho_{v}}\right)^{0.7}\left(\frac{T_{\text {sat }} c_{P} \sigma \rho_{l}}{L^{2} \rho_{v}{ }^{2} l_{c}}\right)^{0.33} \operatorname{Pr}^{-0.45} \text {.(3) }
$$

That of Mc Nelly [37] determines the HTC from the heat flux, the density ratio, some thermo-physical parameters and the working pressure, it is expressed thus:

$$
h=0.225\left(\frac{q c_{p}}{L}\right)^{0.69}\left(\frac{p \lambda}{\sigma}\right)^{0.31}\left(\frac{\rho_{l}}{\rho_{v}}-1\right)^{0.32} .
$$

The HTC is determined directly by the Labuntsov correlation [38] as a function of the thermo-physical parameters and the heat flux:

$$
h=0.075\left[1+10\left(\frac{\rho_{v}}{\rho_{l}-\rho_{v}}\right)^{0.67}\right]\left(\frac{\lambda^{2}}{v \sigma T_{s a t}}\right)^{0.33} q^{0.67} \text {.(5) }
$$

Stephan and Abdeslam [39] developed several correlations adapted to the type of fluid, we chose the one specific to cryogenic fluids, it is in the form:

$$
\begin{gathered}
\frac{h d}{\lambda}=4.82\left(\frac{q d}{\lambda T_{\text {sat }}}\right)^{0.624}\left(\frac{\rho_{h} c_{P h} \lambda_{h}}{\rho_{l} c_{P} \lambda}\right)^{0.117} \\
\left(\frac{\rho_{v}}{\rho_{l}}\right)^{0.257}\left(\frac{c_{P} T_{\text {sat }} d^{2}}{a^{2}}\right)^{0.374}\left(\frac{L d^{2}}{a^{2}}\right)^{0.329} .
\end{gathered}
$$

And $d$ is the diameter of the bubble will be calculated by this formulation:

$$
d=0.0146 \beta\left(\frac{2 \sigma}{g\left(\rho_{l}-\rho_{v}\right)}\right)^{0.5} .
$$

The Shekriladze correlation [40] gives the Nusselt as a function of two dimensionless groups, which depends on the thermo-physical parameters:

$$
\frac{h r_{0}}{\lambda}=0.88 \times 10^{-2}\left(\frac{q r_{0}{ }^{2} \rho_{v} L}{\sigma \lambda T_{\text {sat }}}\right)^{0.7}\left(\frac{c_{p} T_{\text {sat }} \sigma \rho_{l}}{L^{\frac{3}{2}} \rho_{v}{ }^{2} v}\right)^{0.25} .
$$

\section{COMPARISON WITH CORRELATIONS}

The experimental data collected were compared with the values predicted by the correlations, for nucleation, critical heat flux and nucleate boiling.

The thermo-physical characteristics of the fluid for the different pressures were taken from the NIST site (National Institute of Standards and Technology) [41] and from the document Selected Proprieties of Hydrogen [42].

In order to achieve a qualitative evaluation of the values predicted by the correlations, a statistical approach is introduced in addition to the graphic visualization. 
Tab. 1. Experimental data of nucleate pool boiling

\begin{tabular}{|c|c|c|c|c|c|c|c|c|}
\hline Reference & Author/Year & Heater type & $\begin{array}{l}\text { Heater Dimensions } \\
\qquad \text { (m) } \times 10^{-3}\end{array}$ & Roughness & $\Delta \mathrm{T}(\mathrm{K})$ & $\mathrm{q}\left(\mathrm{W} / \mathrm{m}^{2}\right) \times 10^{3}$ & $\mathrm{p}(\mathrm{Pa}) \times 10^{5}$ & Points \\
\hline 15 & $\begin{array}{c}\text { Weil and } \\
\text { Lacaze A } \\
(1951)\end{array}$ & Wire/Pb & $\mathrm{d}=0.4$ & ND & $0.28-1.92$ & $0.24-28.51$ & 1 & 9 \\
\hline 16 & $\begin{array}{l}\text { Class et al. } \\
\text { (1960) }\end{array}$ & Plate/Alloy & $560 \times 25.4 \times 0.0013$ & $\begin{array}{l}\text { Smooth } \\
\text { surface }\end{array}$ & $0.13-1.85$ & $0.08-3.98$ & $0.83-8.82$ & 38 \\
\hline 17 & $\begin{array}{c}\text { Drayer and } \\
\text { Timmerhaus } \\
(1962)\end{array}$ & $\begin{array}{c}\text { Tube vertical } \\
\text { Bronze }\end{array}$ & $d=16 ; \lg =113$ & $\begin{array}{l}\text { 16-32 ASA } \\
\text { finish }\end{array}$ & $0.03-0.65$ & $0.07-3.09$ & 0.83 & 19 \\
\hline 18 & $\begin{array}{l}\text { Sherley } \\
(1963)\end{array}$ & $\begin{array}{l}\text { Horizontal } \\
\text { plate/Glass }\end{array}$ & $244 \times 76.2 \times 1$ & ND & $1.10-6.25$ & $0.72-77$ & 1.013 & 100 \\
\hline 19 & $\begin{array}{l}\text { Graham et } \\
\text { al. (1965) }\end{array}$ & $\begin{array}{c}\text { Ribbon/Chromel } \\
\text { A }\end{array}$ & ND & ND & $0.17-4.07$ & $0.18-141$ & $2.93-6.85$ & 69 \\
\hline 20 & $\begin{array}{l}\text { Astruc } \\
(1967)\end{array}$ & Wire/Pt & $\mathrm{d}=0.1 ; \lg =490$ & ND & $1.17-1.99$ & $2.84-49.6$ & 1 & 33 \\
\hline 21 & $\begin{array}{l}\text { Coeling and } \\
\text { Merte } \\
(1969)\end{array}$ & $\begin{array}{l}\text { Disk/Cu , SS } \\
\text { Teflon }\end{array}$ & $\mathrm{d}=25.4 \mathrm{t}=12.7$ & $\mathrm{Ra}=4-31 \mu \mathrm{m}$ & $0.19-3.96$ & $0.12-105$ & 1.19 & 262 \\
\hline 22 & $\begin{array}{l}\text { Merte } \\
(1970)\end{array}$ & $\begin{array}{c}\text { Sphere / Cu, disk } \\
\mathrm{Cu}, \text { Wire/Pt }\end{array}$ & $\begin{array}{c}\text { Sphere } \mathrm{d}=24.4 ; \\
\text { disk } \mathrm{A}=645 ; \text { Wire } \\
\mathrm{d}=0.14\end{array}$ & ND & $0.19-3.96$ & $0.12-105$ & 1.19 & 75 \\
\hline 23 & $\begin{array}{l}\text { Bland et al. } \\
\text { (1973) }\end{array}$ & Disk/Cu & $\mathrm{d}=20 ; \lg =20$ & Polished & $0.09-1.62$ & $0.09-5.61$ & 3.25 & 10 \\
\hline 24 & $\begin{array}{c}\text { Bewilogua } \\
\text { al. (1975) }\end{array}$ & Disk/Cu & $\mathrm{A}=2.910^{4}$ & ND & $0.10-1.91$ & $1.99-83.3$ & $1-9.7$ & 58 \\
\hline 25 & $\begin{array}{l}\text { Kirichenko } \\
\text { al. (1990) }\end{array}$ & Cylinder / Steel & $\mathrm{d}=30 ; \mathrm{t}=12.5$ & $\mathrm{Ra}=0.4 \mu \mathrm{m}$ & $0.06-16.02$ & $0.27-109$ & $0.07-1$ & 58 \\
\hline 26 & $\begin{array}{l}\text { Kozlov and } \\
\text { Nozdrin } \\
(1992)\end{array}$ & $\begin{array}{c}\text { Disk / Steel, Al } \\
\text { Alloy, } \mathrm{Cu}\end{array}$ & $\mathrm{d}=30 ; \mathrm{t}=8-18-12$ & ND & $0.67-27.93$ & $0.83-113$ & $0.072-1.3$ & 129 \\
\hline 27 & Sindt (1995) & Disk/Cu & $\mathrm{d}=25.4 ; \mathrm{t}=19$ & ND & $0.12-6.10$ & $0.08-78.80$ & 1.013 & 53 \\
\hline 28 & $\begin{array}{l}\text { Ohira } \\
(2003)\end{array}$ & Disk/Cu & $d=25$ & $\mathrm{Ra}=0.2 \mu \mathrm{m}$ & $0.10-2.45$ & $0.35-11$ & $0.069-1.013$ & 187 \\
\hline 29 & $\begin{array}{l}\text { Shirai et al. } \\
\text { (2010) }\end{array}$ & Plate/Manganin & $100 \times 10 \times 0.1$ & ND & $1.04-3.63$ & $6.64-128$ & $1.1-9$ & 40 \\
\hline 30 & $\begin{array}{l}\text { Shiotsu et } \\
\text { al. (2012) }\end{array}$ & Plate/SUS316 & $60 \times 5 \times 0.1$ & ND & $3.64-8.99$ & $2.12-220$ & 1.04 & 20 \\
\hline 31 & $\begin{array}{l}\text { Tatsumoto } \\
\text { et al. (2015) }\end{array}$ & Plate/Manganin & $100 \times 10 \times 0.1$ & ND & $1.20-4.1$ & $1.15-107$ & $1-11$ & 40 \\
\hline
\end{tabular}




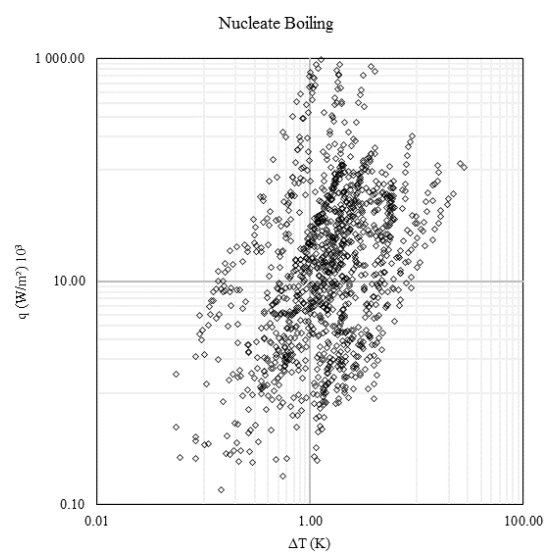

Fig. 4. Heat flux vs difference temperature of experiment data [15-31]

The comparison of the experimental data with that predicted of the heat flux and the HTC by each of the chosen correlations, will be done with the error and correlation coefficient parameters defined below:

$$
\begin{gathered}
\text { Error }=\frac{\left|q_{\text {cal }}-q_{\text {exp }}\right|}{q_{\text {exp }}} \\
\text { Mean Error } \frac{\sum_{i=1}^{n} \text { Error }_{i}}{n} \\
r=\frac{\text { covariance }_{q_{\text {exp }} q_{c a l}}}{\text { variance }_{\text {exp }} \text { variance } q_{\text {cal }}}
\end{gathered}
$$

\subsection{The ONB comparison}

The relationship giving the heat flow required for the start of nucleation is determined by the correlation (1), was compared with the experimental data collected from the experimental setups, by viewing the appearance of the first bubbles.

The analysis of the values collected shows us that two series of points are distant from the lot, the first series is that of the work of Ohira [28] which gives higher values in heat flux for the same value of the points overheating compared to $[21,26]$. The second series concerns the points where the pressure is $7 \times 10^{5}$ Pa from the work of Shiotsu et al. [30]. The heat flux of the points [28] have been divided by a factor of 10 since we think that there is an error of scale, the second series has been discarded, the set of the new points are shown in figure 5. From this fact, a trend curve was formulated by the method of least squares, linking the heat flux to the temperature difference for the case of the appearance of the first bubbles of the nucleate boiling of hydrogen, and presented under the correlation form of the type $q_{O N B}=C \Delta T^{n}$.

The formulation of the ONB heat flux $q$ of appearance of the first bubbles is indicated by the correlation (12), see below:

$$
q_{O N B}=550 \Delta T^{1.32}
$$

Liu et al. [43] reviewed the authors who studied the start of the first bubbles by presenting an illustrative and comparative table for calculating the heat flux; the values predicted by the correlation (1) of Hsu [34] gives a large deviation and a more pronounced slope, the curve of the correlation (1) plotted in Figure 5 was calculated for a pressure of $10^{4}$ $\mathrm{Pa}$, for higher pressure values the difference becomes much greater. The correlation (1) does not apply to liquid hydrogen, it is valid for other fluids. On the other hand, the correlation (12) gives acceptable results with an average error of $58 \%$ and a correlation coefficient equal to 0.77 compared to the experimental data.

ONB

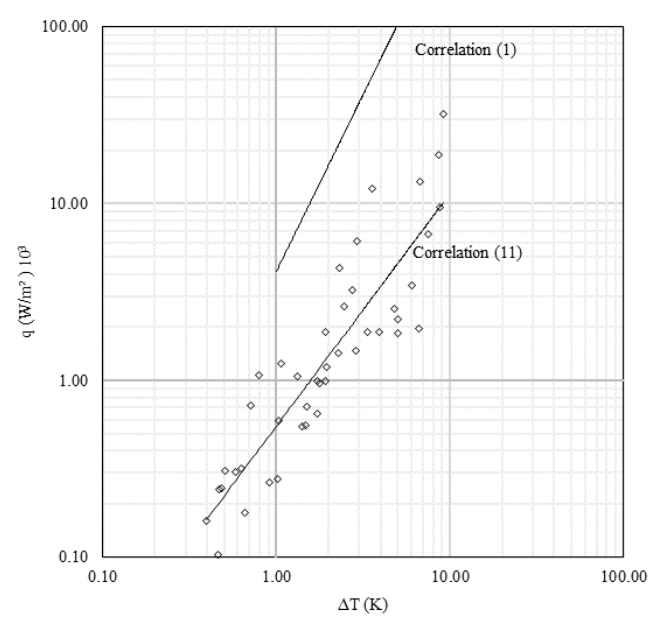

Fig. 5. Comparison of the ONB values and correlation

\subsection{The CHF comparison}

The analysis of the experimental data of the CHF point us a vertical juxtaposition for the same reduced pressure, therefore the points of the experiments $[28,30]$ were excluded from the study since they relate to another aspect of research. The predicted CHF is determined by the Kutateladze correlation (2), and in order to determine the coefficient $\mathrm{C}$, we have made the ratio between the $\mathrm{CHF}$ and the thermophysical characteristics, as indicated in equation (13) for each pressure of the points collected, see Figure 6. The correlation (14) of the coefficient $\mathrm{C}$ is deduced with a maximum smoothing of the points obtained.

$$
\begin{gathered}
C=\frac{q_{c}}{L \rho_{v}\left[\frac{g \sigma\left(\rho_{l}-\rho_{v}\right)}{\rho_{v}^{2}}\right]^{1 / 4}} \\
C=-0.2926\left(\frac{p}{p_{c}}\right)^{2}+0.2047\left(\frac{p}{p_{c}}\right)+0.1586(14)
\end{gathered}
$$

Kutateladze [35] found a valid range for the coefficient $\mathrm{C}$ and used an average value of 0.16 ; similarly Beliwoga et al. [24] used the value of 0.16 and found good results for hydrogen. Wang et al. [14] deduced a correlation for the coefficient $\mathrm{C}$ from experimental data and have achieved convenient results. 
One compared the values predicted by different coefficients with the experimental data, the graphical analysis on Figure 6 shows that for the value of 0.16 the curve is located on one side below and the other at above the points, other values were counted and better results were obtained with the value of 0.18 . The correlation (14) of the coefficient $\mathrm{C}$ perfectly matches the point cloud over the entire band. A statistical comparison indicates that the coefficient obtained with the correlation (14) gives values of CHF with the minimum of error, the value $\mathrm{C}=0.18$ is a constant numerical coefficient easy to use gives convincing results. Correlation (14) is a polynomial of the second degree, the extremum is calculated by determining the derivative, so the CHF locates at $\frac{p}{p_{c}}=0.35$ and reaches the value of $148 \times 10^{3} \mathrm{~W} / \mathrm{m}^{2}$.

$\mathrm{CHF}$

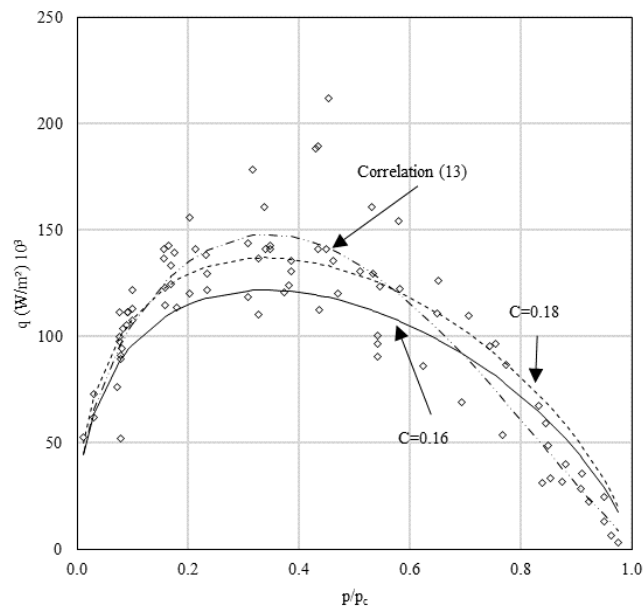

Fig. 6. Comparison of $\mathrm{CHF}$ data and correlations

\subsection{The Nucleate Boiling comparison}

The predicted HTC with the previously cited correlations from (3) to (7) were compared with the 1200 values of the experimental HTC, graphs have been drawn, see Figure 7 to Figure 11.

\section{Kruzhlin's Correlation}

Satisfactory values were determined with correlation (3) with a result of a correlation coefficient equal to 0.86 and an error mean of $90 \%$, as shown in Figure 7 , a concentration of points along the midline with scattered points above and below, the high experimental values are underestimated by the Kruzhlin correlation.

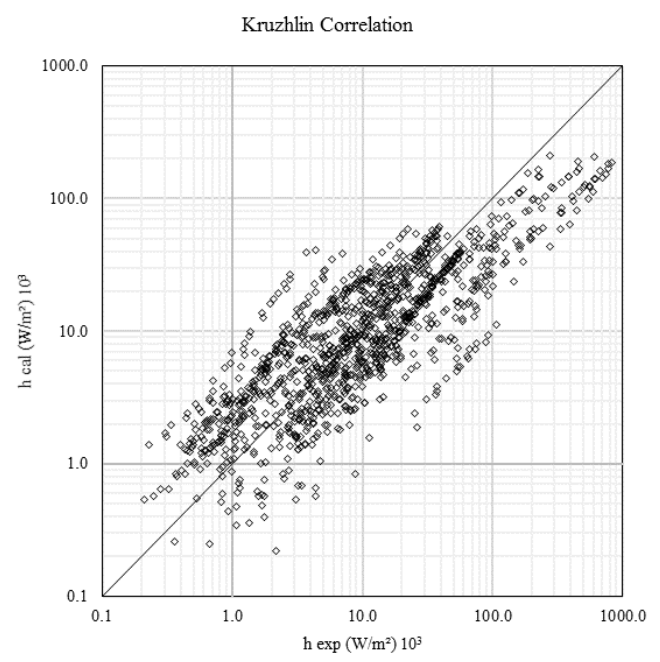

Fig. 7. Comparison of Kruzhilin correlation and data

\section{Mc Nelly's Correlation}

Values have been determined with the correlation (4) giving a correlation coefficient of 0.77 and an error mean of $66 \%$, Figure 8 shows a large dispersion of points over a large area at the top and bottom of the median line.

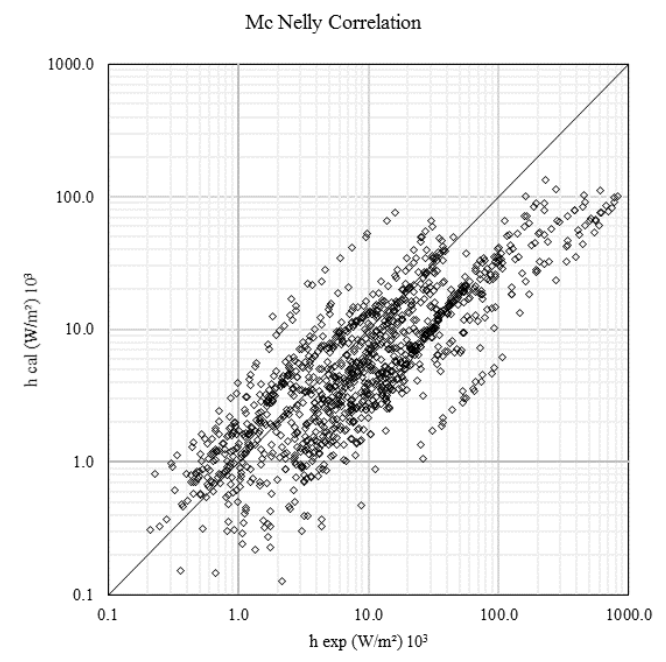

Fig. 8. Comparison of Mc Nelly correlation and data

\section{Labuntsov Correlation}

A concentration of points, see Figure 9, in the middle with values far from the median, these values were determined with the correlation (5), the results indicate a correlation coefficient of 0.71 and a mean error of $100 \%$. 


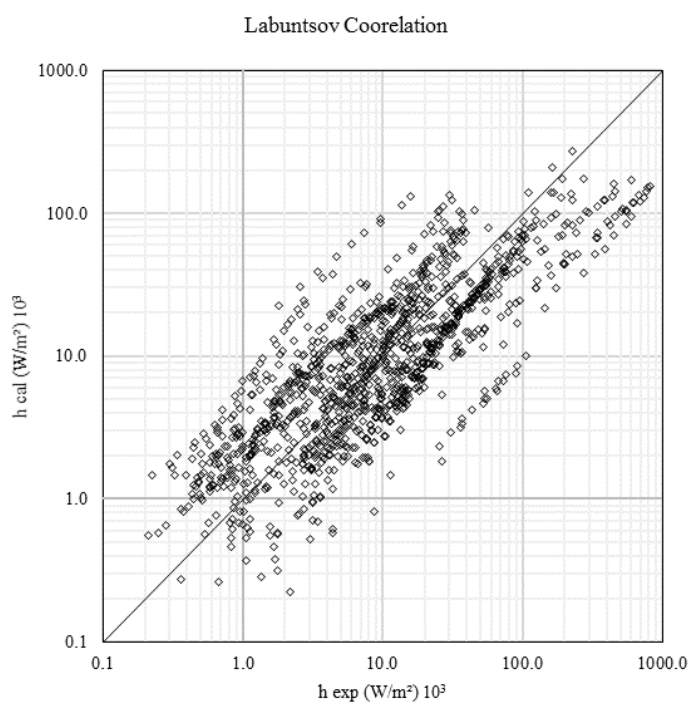

Fig. 9. Comparison of Labuntsov correlation and data

\section{Stephan and Abdisalam's Correlation}

To calculate the predicted values with the correlation (6) of Stephan and Abdessalam a modification in the formulation was made by changing the coefficient by $4.82 \times 10^{-7}$, values were then determined with a correlation coefficient of 0.75 and an average error of $84 \%$. The correlation (6) requires the data of the parameters of the heating element, certain values of experience have been discarded [16] because the material heater is non defined, others have been replaced by the values of Aluminum since it is undefined Aluminum Alloy [26]. Figure 10 shows a concentration of points in the middle with a series of points scattered at the top and bottom of the center line.

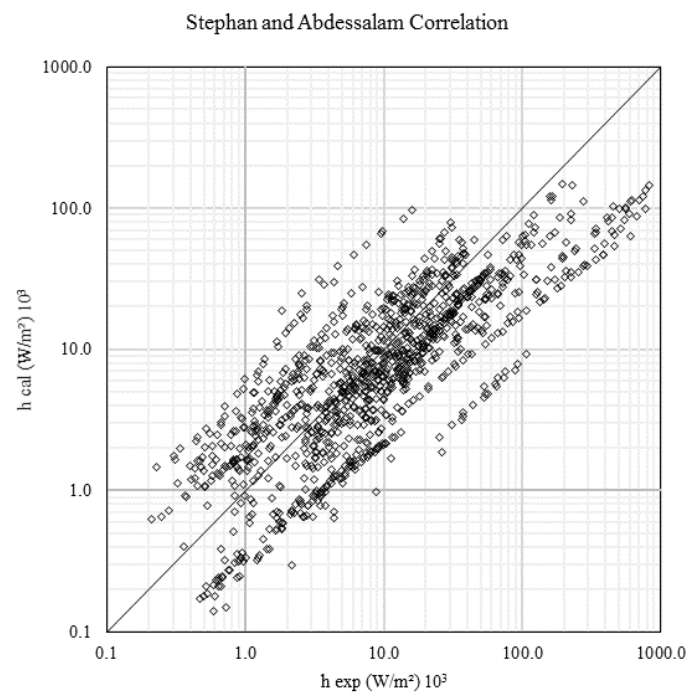

Fig. 10. Comparison of Stephan and Abdelsalam correlation and data

\section{Shekriladze Correlation}

Figure 11 shows a large concentration along the median and scattered points on both sides, predicted values were calculated with the correlation (8) resulting in a correlation coefficient of 0.81 and an error mean of $126 \%$.

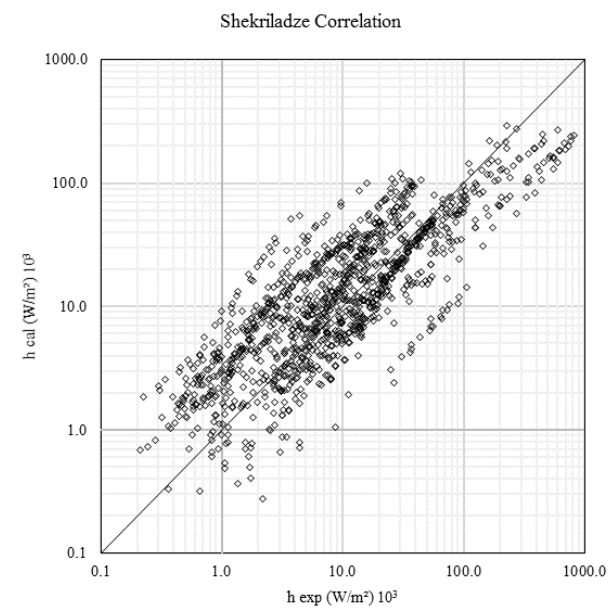

Fig. 11. Comparison of Shekriladze correlation and data

\section{New correlation}

Based on the approach of Touhami et al. [44], we took general form of the Nusselt $N u=c \operatorname{Re}^{n} \operatorname{Pr}^{m}$, we consider that the pressure and the density ratio have an effect on the behavior of the fluid, we added two dimensionless groups $p / p_{c}$ and $\rho_{v} / \rho_{l}$.

After several iterative tests we arrived at the expected results of the new correlation (15), namely a coefficient of 0.86 and an average error of $84 \%$, which is considered convincing results. Figure 12 illustrates a homogeneous concentration of the points along the median line, the predicted values are underestimated for the large values.

$$
\frac{h l_{c}}{\lambda}=10\left(\frac{q l_{c}}{\mu L}\right)^{0.67}\left(\frac{\mu c_{p}}{\lambda}\right)^{0.40}\left(\frac{p}{p_{c}}\right)^{0.55}\left(\frac{\rho_{v}}{\rho_{l}}\right)^{-0.75}
$$

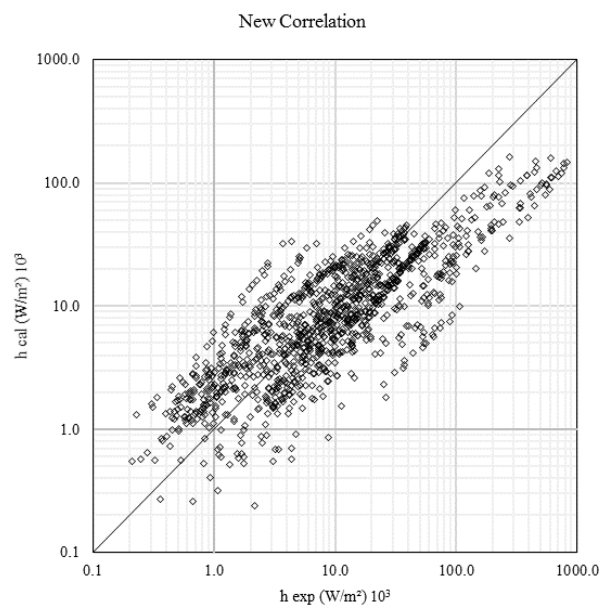

Fig. 12. Comparison of the new correlation and data 


\section{CONCLUSIONS}

A review of experimental data from the literature relating to the onset, nucleate pool boiling and critical heat flux of hydrogen under saturation conditions was carried out by collecting around 1400 points. The study would have been more complete if the references [45-55] were found.

A comparison between the heat flux necessary for ONB predicted by the correlation of Hsu [34] and that experimental was expressed, a significant difference was found. Based on the experimental data giving the necessary heat flux as a function of the temperature difference, a new correlation (12) has been deduced, indicating acceptable results.

The coefficient of the Kutateladze correlation [35] giving the critical heat flux was modified and compared to the experimental data collected. Modifications on the value of the coefficient were made, a constant numerical value of 0.18 and a correlation (14) function of the reduced pressure gave better results. In all cases the CHF follows an ascending curve, goes through a peak, then decreases, the extremum locates at $\frac{p}{p_{c}}=0.35$ where the value of CHF reaches $148 \times 10^{3} \mathrm{~W} / \mathrm{m}^{2}$ according to the correlation (2)

Five correlations drawn from the literature giving the heat transfer coefficient of the nucleate pool boiling were tested for hydrogen under saturation conditions. Two correlations, that of Kruzhlin followed by that of Shekriladze, gave results in good agreement with the experimental data compared to the other three.

A new correlation (15) has been presented allowing the calculation of the heat transfer coefficient as a function of the heat flux and the thermal-physical characteristics of hydrogen, giving convincing results.

\section{Nomenclature}

\section{Symbols}

$a \quad-\quad$ thermal diffusivity, $\mathrm{m}^{2} / \mathrm{s}$

$A$ - area, $\mathrm{m}^{2}$

C - coefficient

$c_{p}-$ heat capacity, $\mathrm{J} /(\mathrm{kg} . \mathrm{K})$

$d \quad-$ diameter, $\mathrm{m}$

$g \quad-\quad$ gravity acceleration, $\mathrm{m} / \mathrm{s}^{2}$

$h$ - heat transfer Coefficient, $\mathrm{W} /\left(\mathrm{m}^{2} . \mathrm{K}\right)$

$l_{c} \quad$ - Capillary length, $\mathrm{m}$

$l g$ - length, $\mathrm{m}$

$L \quad$ - latent heat of vaporization, $\mathrm{J} / \mathrm{kg}$

$\mathrm{Nu}$ - Nusselt Number

$p$ - pressure, $\mathrm{Pa}$

$P r$ - Prandtl Number

$q$ - heat flux, $\mathrm{W} / \mathrm{m}^{2}$

$r \quad-\quad$ correlation coefficient

$r_{o} \quad-\quad$ radius of the nucleation site, $\mathrm{m}$

$R_{a}-$ arithmetic roughness, $\mu \mathrm{m}$

Re - Reynolds Number

$t \quad$ - thickness, $\mathrm{m}$

$T$ - Temperature, $\mathrm{K}$

\section{Greek symbols}

$\beta \quad-\quad$ angle contact, degree

$\Delta$ - difference

$\lambda \quad-\quad$ thermal conductivity, W/(m.K)

$\mu$ - dynamic viscosity, Pa.s

- kinematic viscosity, $\mathrm{m}^{2} / \mathrm{s}$

- density, $\mathrm{Kg} / \mathrm{m}^{3}$

$\sigma \quad-\quad$ surface tension, $\mathrm{N} / \mathrm{m}$

\section{Subscript}

$c \quad-$ critic

cal - calculated

exp - experimental

$h-$ heater

$l-$ liquid

$v$ - vapor

sat - saturated

\section{References}

1. Aversa R, Petrescu V, Apicella A, Petrescu IT. (2016). The basic elements of life's. Am J Eng Appl Sci, Vol. 9; pp.1189-97

2. McCarty RD, Hord J, Roder HM. (1981). NBS Monograph: Selected Properties of Hydrogen

3. Smith PM. (2007) The History and Use of Our Earth's Chemical Elements: A Reference Guide, 2nd Edition (Robert E. Krebs). J Chem Educ, Vol. 84; pp. 1767

4. Holladay JD, Hu J, King DL, Wang Y. (2009). An overview of hydrogen production technologies. Catal Today, Vol. 139; pp. 244-60

5. Baykara SZ. (2018) Hydrogen: A brief overview on its sources, production and environmental impact. Int $J$ Hydrogen Energy, Vol. 43; pp.10605-14

6. Zhou L. (2005). Progress and problems in hydrogen storage methods. Renew Sustain Energy Rev, Vol. 9; pp. 395-408

7. Andersson J, Grönkvist S. (2019) Large-scale storage of hydrogen. Int J Hydrogen Energy, Vol. 44; pp. 11901-19

8. Eklund G, Von Krusenstierna O. (1983). Storage and transportation of merchant hydrogen. Int J Hydrogen Energy, Vol. 8; pp. 463-70

9. Richards RJ, Steward WG, Jacobs RB. (1961). A Survey of the Literature on Heat Transfer from Solid Surfaces to Cryogenic Fluids. Advances

10. Seader JD, Miller WS, Kalvinskas LA. (1965). Boiling heat transfer for cryogenics. NASA CR-243

11. Brentari EG, Giarratano PJ, Smith R V. (1965). Boiling heat transfer for oxygen, nitrogen, hydrogen, and helium. vol. 4

12. Drayer DE. (1965) Nucleate boiling of hydrogen: Comparison between Experimental and Predicted Data. Ind Eng Chem Fundam

13. McDougall IR. (1971). The boiling of cryogenic fluids-a survey. Cryogenics (Guildf) Vol. 11; pp. 260-7

14. Wang L, Li Y, Zhang F, Xie F, Ma Y. (2016) Correlations for calculating heat transfer of hydrogen pool boiling. Int J Hydrogen Energy, Vol. 41; pp. 17118-31

15. Weil L, Lacaze A. (1951). Échanges de chaleur dans l'hydrogène bouillant sous pression atmosphérique. $J$ Phys Le Radium

16. Class CR, DeHaan JR, Piccone M, Cost RB. (1960) Boiling Heat Transfer to Liquid Hydrogen from Flat Surfaces. Adv Cryog Eng ; pp.254-61

17. Drayer DE, Timmerhaus KD. (1962) An Experimental Investigation of the Individual Boiling and Condensing Heat-Transfer Coefficients for Hydrogen. Adv Cryog Eng 
18. Sherley JE. (1963). Nucleate Boiling Heat-Transfer Data for Liquid Hydrogen at Standard and Zero Gravity. Adv Cryog Eng, pp. 495-500

19. Graham RW, Hendricks RC, Ehlers RC. (1964) An experimental study of the pool heating of liquid hydrogen in the subcritical and supercritical pressure regimes over a range of accelerations. NASA TM X52039

20. Astruc, J. M. (1967). Échanges thermiques superficiels dans le néon, le deutérium et l'hydrogène liquides bouillants en convection libre et flux de chaleur critiques en convection forcée du néon liquide (Doctoral dissertation)

21. Coeling, K. J., \& Merte Jr, H. (1969). Incipient and nucleate boiling of liquid hydrogen. J. Eng. Ind. May 1969, Vol. 91; No. 2; pp. 513-519

22. Merte H. (1970). Incipient and steady boiling of liquid nitrogen and liquid hydrogen under reduced gravity

23. Bland ME, Bailey CA, Davey G. (1973) Boiling from metal surfaces immersed in liquid nitrogen and liquid hydrogen. Cryogenics (Guildf), Vol. 13; pp. 651-7

24. Bewilogua L, Knöner R, Vinzelberg H. (1975) Heat transfer in cryogenic liquids under pressure. Cryogenics (Guildf), Vol. 15; pp. 121-5

25. Kirichenko YA, Kozlov SM, Nozdrin S V. (1990) Heat exchange with boiling hydrogen on the surface of heater of steel 12Kh18N10T. Chem Pet Eng, Vol. 26; pp.41722

26. Kozlov SM, Nozdrin S V. (1992) Heat transfer and boundaries of its regimes during hydrogen boiling at different metallic surfaces. Cryogenics (Guildf)

27. Sindt CF. (1995). Heat transfer to slush hydrogen. In Advances in Cryogenic Engineering; Vol. 19; pp. 427. 436. Springer, Boston, MA

28. Ohira K. (2003) Study of nucleate boiling heat transfer to slush hydrogen and slush nitrogen. Heat Transf - Asian Res, Vol.32; pp. 13-28

29. Shirai Y, Tatsumoto H, Shiotsu M, Hata K, Kobayashi $\mathrm{H}$, Naruo Y, et al. (2010) Boiling heat transfer from a horizontal flat plate in a pool of liquid hydrogen. Cryogenics (Guildf), Vol. 50; pp. 410-6

30. Shiotsu M, Kobayashi H, Takegami T, Shirai Y, Tatsumoto H, Hata K, et al. (2012). Transient heat transfer from a horizontal flat plate in a pool of liquid hydrogen. AIP Conf Proc, Vol. 1434; pp. 1059-66

31. Tatsumoto H, Shirai Y, Shiotsu M, Naruo Y, Kobayashi H, Inatani Y. (2015) Heat Transfer Characteristics of a Horizontal Wire in Pools of Liquid and Supercritical Hydrogen. J Supercond Nov Magn

32. Ohk SM, Chung BJ. (2017) Visualization of CHF varying the Surface Orientation using Non-heating Method. Proceedings of the KNS 2017 Spring Meeting

33. Roubeau, P. (1961). Heat exchanges in nitrogen and hydrogen boiling under pressure . $10 \mathrm{p}$; Proceedings of the $10^{\text {th }}$ international congress of refrigeration; Copenhague (Denmark)

34. Hsu YY. (1962) On the size range of active nucleation cavities on a heating surface. J Heat Transfer, Vol. 84; pp. 207-13

35. Kutateladze, S. S., (1948). On the Transition to Film Boiling under Natural Convection, Kotloturbostroenie, No. 3, pp. 10-12

36. Kruzhilin G. N. (1947). Free-convection transfer of heat from a horizontal plate and boiling liquid. Doklady AN SSSR (Reports of the USSR Academy of Sciences), Vol. 58; No. 8; pp. 1657-1660

37. Mc Nelly M. J. A correlation of rates of heat transfer to nucleate boiling of liquids. J. Imperial

38. Labuntsov D.A. (1972) Heat transfer problems with nucleate boiling of liquids, Therm. Eng. Vol. 19; No. 9; pp. $21-28$
39. Stephan K, Abdelsalam M. (1980) Heat-transfer correlations for natural convection boiling. Int J Heat Mass Transf, Vol. 23; pp. 73-87

40. Shekriladze IG. (2008) Boiling Heat Transfer: Mechanisms, Models, Correlations and the Lines of Further Research. Open Mech Eng J, Vol. 2; pp. 104-27.

41. NIST Chemistry Webbook, NIST standard reference database number 69, October 2011 release

42. McCarty RD, Hord J, Roder HM. (1981) Selected Properties of Hydrogen (Engineering Design Data)

43. Liu D, Lee PS, Garimella S V. (2005). Prediction of the onset of nucleate boiling in microchannel flow. Int J Heat Mass Transf, Vol. 48; pp. 5134-49

44. Touhami B, Abdelkader A, Mohamed T. (2014). Proposal for a correlation raising the impact of the external diameter of a horizontal tube during pool boiling. Int J Therm Sci, Vol. 84; pp. 293-299

45. Hoge HJ, Brickwedde FG. (1942) Rate of heat transfer from a horizontal heated copper tube in boiling liquid hydrogen or oxygen. private communication 1942

46. Weil L. (1951) Heat transfer coefficients of boiling liquified gases. In Proc. Intern. Congr. Refrig., 8th, London. Comite Congres Intern. du Froid Paris 1951

47. Mulford RN, Nigon JP. (1952) Heat exchange between a copper surface and liquid hydrogen and nitrogen (No. LA-1416). Los Alamos Scientific Lab. 1952

48. Class CR, DeHaan JR, Piccone M, Cost RB (1958). Pool boiling heat transfer to a cryogenic liquid. WADC Tech. Rept. Vol. 58; pp. 528

49. Malkov MP, Zeldovitch AG, Fradkov AB, Danilov IB. (1959). Industrial separation of deuterium by lowtemperature distillation (No. A/CONF. 15/P/2323). USSR. 1959

50. Timmerhaus KD, Drayer DE, Dean JW. (1961). An Experimental Investigation of Overall Heat Transfer Coefficients for Condensing and Boiling Hydrogen Films. In Int. Heat Transfer Conf., Boulder (Colo.) Vol. 28

51. O'Hanlon TW. (1962) Zero-g Report, LH2 Nucleate Boiling, General Dynamics/Astronautics Report 5SD859-1, 1962

52. Kouling K, Mert G. (1969) Nucleate boiling and its onset in liquid hydrogen. Konstruirovanie Tekhn. Mashinostroeniya, Vol. 91; No. 2; pp. 237-242

53. Clark D.A. (1971). Cryogenic heat transfer, in Uspekhi Teploperedachi, W.M. Rohsenow and J.P. Hartnet, Eds. Moscow: Mir Press 1971; pp. 361-367

54. Grigoriev VA, Pavlov YM, Ametistov EV. (1973) Boiling of Cryogenic Liquids. Moscow: Energia Press

55. Kirichenko IA, Levchenko NM, Kozlov SM. (1977). Heat release during boiling of hydrogen in a large volume. Teploenergetika, Vol. 60; pp. 63

\section{Biographical note}

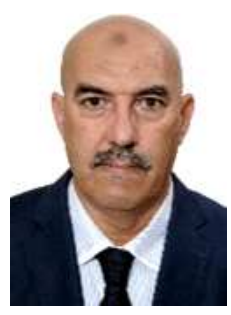

Touhami Baki is a lecturer at the Faculty of Mechanics, University of Science and Technology of Oran Mohamed Boudiaf, Algeria. He obtained his engineering degree in industrial maintenance in 1984. He worked in the industrial field for more than 20 years, he then joined the university where he obtained the diploma of Magister in 2011, the doctorate in 2016 at University of Science and Technology USTO-MB, Oran, Algeria. His research areas are heat transfer, boiling, bubble dynamics, solar water heaters. 